\title{
AMARAL, EMILIA. PARA AMAR CLARICE: COMO DESCOBRIR E APRECIAR OS ASPECTOS MAIS INOVADORES DE SUA OBRA. BARUERI, SP: FARO EDITORIAL, $2017,160 \mathrm{p}$.
}

\author{
Antônia de Jesus Sales \\ Instituto Federal de Educação, Ciência e Tecnologia do Ceará, Fortaleza, Ceará, Brasil \\ antonia_saless@hotmail.com
}

Andréia Guerini Universidade Federal de Santa Catarina, Florianópolis, Santa Catarina, Brasil andreia.guerini@gmail.com

Para Amar Clarice: como descobrir e apreciar os aspectos mais inovadores de sua obra é um livro que foi lançado no momento em que se comemoravam os 40 anos de morte da escritora e que se propõe como um itinerário e também como uma espécie de guia sobre como descobrir e apreciar os aspectos inovadores da obra de Clarice Lispector.

O livro é dividido em 8 capítulos, todos com excertos da obra e diversas imagens: 1) Perfil da autora; 2) Dar voz ao que é silenciado; 3) A ficção como exercício da aventura humana: perfis singulares; 4) Cumplicidade entre narrador e personagens: a interioridade; 5) A arte de tocar o inexpressivo; 6) Uma (des)montagem da tradição; 7) A escrita caleidoscópica ou de como (não) se tocar a coisa com a palavra; 8) Para amar mais Clarice.

No texto de apresentação, Amaral define Clarice como uma escritora "[...] que viveu e escreveu sob os signos da fascinação e do paradoxo: adorada por muitos, eleita como objeto de várias tendências críticas, ao mesmo tempo, avessa a diferenciações de gênero, entre outras categorias classificatórias" (2017, p. 9).

No primeiro capítulo, conforme o título indica, "Perfil da autora", Amaral apresenta aspectos biográficos de Clarice, trazendo informações sobre a vida, assim como suas primeiras aventuras no mundo da literatura até a publicação do seu primeiro romance, Perto do coração selvagem, de 1943. Aqui também encontramos relatos de Sérgio Milliet, Lúcio Cardoso e Antonio Cândido, que escreveram críticas positivas, mas também de Álvaro Lins, que discordava do formato da narrativa da primeira publicação de Clarice.

Nesse capítulo encontramos uma lista dos prêmios recebidos pela autora e informa ainda sobre as traduções das obras de Clarice, como a de $A$ maçã no escuro para o alemão, que aconteceu na década de 60 do século XX, e para o francês na década de 70 . Ao final do capítulo, Amaral oferece um guia de obras claricianas, em ordem de publicação.

Em "Dar voz ao que é silenciado", a autora chama a atenção para uma característica comum à obra de Clarice: dar voz aos personagens femininos. Para exemplificar, Amaral cita a última obra, publicada dois meses antes de sua morte, A Hora da Estrela, de 1977, que é considerada seu testamento literário. A discussão, segundo Amaral, é relevante porque essa é uma obra que "ao mesmo tempo contém, num tom bastante particular, seus principais temas, personagens, imagens e traços estilísticos." (p. 29). A análise é permeada por excertos, que servem de exemplo para tratar do desenvolvimento do enredo de A Hora da estrela e o processo criativo de Clarice. Ao final do capítulo, a autora oferece ao leitor, como leitura 
complementar, um trecho dos contos A menor mulher do mundo e Uma galinha, inseridos em Laços de família, de 1960, relacionando com um trecho de $A$ Hora da estrela.

No terceiro capítulo, "A ficção como exercício da aventura humana", Amaral faz um passeio por Perto do coração selvagem, livro de estreia de Clarice, de 1943. Nele, segundo Amaral, encontramos: "a aventura da expressão, a intensidade em captar nuances da vida interior, a rara ênfase na sensibilidade." (p. 46) tendo como pano de fundo a vida de Joana "cuja travessia existencial é marcada tanto pelo fato de estar viva quanto por buscar incessantemente o sentido da existência, o selvagem coração da vida. [...]" (p. 46). Desta forma, a personagem não separa o seu existir do fato de se perceber existindo ao expressar suas percepções. Amaral chama a atenção para o aspecto de que em Perto do coração selvagem, os capítulos e os acontecimentos ficam em segundo plano em detrimento das sensações e reflexões de Joana, que acabam constituindo a essência da obra. Como leitura complementar, Amaral faz um paralelo entre as personagens Joana, de Perto do coração selvagem e Sofia, do conto "Os desastres de Sofia".

No quarto capítulo, "Cumplicidade entre narrador e personagens", Amaral nos apresenta Laços de família, publicado em 1960 e composto por 13 contos, sendo que oito deles lidam com o feminino no âmbito familiar. O capítulo se subdivide em três tópicos: apresentação, desenvolvimento e o feminino como alienação e transgressão. Amaral analisa as características principais do enredo, com partes de alguns contos. Quanto à questão feminina, Amaral chama a atenção para o fato de as personagens, em sua maioria do sexo feminino, transitarem no universo familiar, e, assim, uma interrupção da rotina dos personagens e a volta à rotina podem ser considerados o ponto forte dos contos da obra Laços de Família.

No quinto capítulo, "A arte de tocar o inexpressivo", Amaral questiona a forma como Clarice provoca o leitor com sua narrativa ritualística. Sobre $A$ paixão segundo G. $H$., a autora afirma que "o livro começa e termina cercado por seis travessões que o isolam do mundo trivial, como se o guardassem para o leitor a quem ele - o livro - escolhesse." (p. 84). Amaral destaca uma série de trechos de A paixão segundo G.H. para explanar e exemplificar a metafísica e o estranhamento provocado pelo texto de Clarice. Como leitura complementar, Amaral traz os contos Perdoando Deus (publicado em Felicidade clandestina, de 1971) e Mineirinho (publicado em Para não esquecer, de 1978), fazendo um contraponto com o texto de A paixão segundo G. H. quanto às características de argumentação.

Em "Uma (des)montagem da tradição", Amaral apresenta uma descrição do aspecto numinoso e complexo da argumentação na obra Uma aprendizagem ou o livro dos prazeres. Diz ela: "[...] iniciada por uma vírgula (sinal gráfico que indica pausa) e terminada com dois pontos (que pressupõe continuação), a narrativa não apresenta propriamente começo nem fim, pois se expande para fora do texto e assim, bem ao gosto de Clarice, confunde-se com a vida" (p. 101). Segundo Amaral, "[...] Clarice quer que a literatura mostre/seja a 'veia grossa' da vida, que nela jorre o sangue de todas as coisas, numa hemorragia que é acolhida por uma inteligência vigilante, luminescente" (p. 101). A fim de fazer um cotejamento da obra Uma aprendizagem ou o livro dos prazeres com outras obras de Clarice, como leitura complementar, Amaral trata do conto Felicidade clandestina, de 1971, pois "o magnetismo daquele que tem acesso ao conhecimento, à iniciação constitui uma das obsessões de Clarice (p. 105)." Ou seja, o papel de Ulisses, no romance, é o mesmo da menina encantada com os livros em Felicidade clandestina.

No sétimo capítulo, "A escrita caleidoscópica ou de como (não) se tocar a coisa com a palavra", Amaral descreve a fragmentação da linguagem em Água viva, que diz: "Trata-se de um texto que fala do ato da criação artística, enquanto ele está acontecendo, em seu processo de se fazer, [...]" (p. 112), pois "essa linguagem fragmentária, que não pretende expressar nada, não está no lugar de nada, quer ser uma 'verdade inventada"' (p. 113). Amaral cita ainda algumas características peculiares e inerentes ao texto clariciano: a "[...] ausência 
de enredo, presença de elementos poéticos, emersão de uma voz altamente múltipla e potente, anulação do espaço e do tempo como categorias narrativas.” (p. 114). A hipótese de Amaral é que Água viva representa a fusão constante entre literatura e vida nas obras de Clarice. O discurso imagético está também no título de suas obras, por exemplo, no título de Água viva, "A enunciadora que é pintora e que fala ora com um amor antigo, ora com o leitor, desenha, esculpe, fotógrafa não os objetos, mas a sombra deles, num escrita que é como uma água-viva [...]" (p. 116). Na parte da leitura complementar, Amaral aborda o conto "Menino a bico de pena", publicado em Felicidade clandestina, de 1971, para um cotejamento do enunciador dentro desse texto e em Água viva, na busca de semelhanças na forma como o mundo humano é representado.

No último capítulo, "Para Amar Clarice", Amaral sintetiza o seu trabalho, e justifica a necessidade de se ler textos literários, que por terem uma possibilidade ampla de significados, abrem portas que não se fecham para o leitor, aguçando a inteligência, a criatividade. Amaral fala sobre a metodologia seguida, explicando sua escolha pelas afinidades temáticas, pelo tempo cronológico das principais obras e a relação dessas com outros textos de Clarice, que partiu "[...] do mais conhecido, do mais palatável, do que provoca mais empatia, para outras propostas menos interessantes, mas talvez mais legíveis [...]" (p. 127).

Neste capítulo final, Amaral comenta "O lustre a A cidade sitiada", discussão permeada por reflexões sobre "A maçã no escuro" e os contos "A quinta história" e "O ovo e a galinha". Amaral faz uma apresentação e resume $O$ lustre, e conclui dizendo: "Este romance, sem capítulos, flui de um só fôlego. Como Perto do coração selvagem, é escrito em terceira pessoa, tem um narrador que também percebe e sente como a personagem central Virgínia - e adere a ela desde o início, acompanhando-a, cronologicamente [...]”. (p. 129). Quanto à Cidade sitiada, Amaral pontua que: "O universo ficcional de Clarice funciona, neste texto, como uma cidade sitiada. Lucrécia Neves é o avesso, a caricatura burlesca de Joana e Virgínia." (p. 130).

Amaral conclui o seu livro com uma breve reflexão sobre a produção por encomenda e a literatura infantil em Clarice.

Para finalizar, podemos dizer que o fato de cotejar contextos de diferentes obras proporciona ao leitor mergulhar na obra de Clarice, ajudando a melhor compreender o rico universo literário da autora.

Esse livro contribui para enriquecer a bibliografia crescente sobre uma das principais escritoras brasileiras e se mostra como uma importante fonte de consulta para leitores que não tem intimidade com a obra de Clarice, mas também para os apaixonados e pesquisadores.

\section{Referências}

Amaral, Emilia. Para Amar Clarice: como descobrir e apreciar os aspectos mais inovadores de sua obra. Barueri, SP: Faro Editorial, 2017, 160 p.

Recebido em: 28 de agosto de 2019

Aceito em: 01 de novembro de 2019

Publicado em: Dezembro de 2019 